important influence on the relation between blood pressure and mortality.

The value of antihypertensive treatment canno be inferred from observational studies in the general population. In the very elderly people with hypertension seem to survive longer than those with lower levels of blood pressure, but this does not necessarily mean that no benefit would be obtained from antihypertensive treatment. Because of the survivorship phenomenon the proportionate benefit from treatment may be less than for younger patients. What matters more is the absolute benefit, and this is likely to be influenced by competing causes of death. We shall not know whether such treatment is worth while until clinical trials have been conducted in the very elderly.

Glasgow Blood Pressure Clinic,

P C WALLER Western Infirmary,

Glasgow G11 6N

1 Anonymous. Build and blood pressure study. Chicago: Society of the Actuaries, 1959 .

2 Aromaa A. Blood pressure level, hypertension and five-yea mortality in Finland. Acta Med Scand [Suppl] 1980;646:43-50. 3 Lindholm L, Lanke J, Bengtsson B, Ejlertsson G, Thulin T, Schersten B. Both high and low blood pressure risk indicators of death in middle-aged males. Acta Med Scand 1985;218: 473-80.

\section{Transplantation of fetal tissues}

SIR,-Drs J M S Pearce (30 April, p 1211) and Dr R Gillon (30 April, p 1212) considered the lack of proved benefit and the ethical problems surrounding the use of fetal tissue transplanted into the brain. We would like to draw attention to a potential hazard of such procedures.

We have performed two transplantations in marmoset monkeys using neural tissue from the fetal ventral forebrain taken at an estimated 80 and 76 days of gestation. The recipient of the tissue from the 80 day fetus had previously had a unilateral ablation of the cholinergic input to the hippocampus using ibotenic acid. ${ }^{1}$ Neural tissue was transplanted into the denervated hippocampus eight days later. After five months the animal had bilateral resection of the fornix and was killed three months later. Staining for acetylcholinesterase showed graft survival and moderate spread within the hippocampus.

The second animal had bilateral resection of the fornix followed one month later by bilateral transplantation of fetal ventral forebrain neurones taken at 76 days' gestation from two fetuses. Ten $\mu$ l of dissociated cell suspension was injected into the hippocampus in each hemisphere. This animal was well for two months but then became ill and was killed three days later.

The brain was cut coronally into blocks and the transplanted tissue was clearly visible. It comprised two large masses, one in each hemisphere, occupying the space normally held by the hippocampus and lateral ventricles from the front of the temporal lobe to the back of the occipital lobe and extending in some places as far as the dorsal cortex. The mass stained positively for Nissl substance but negatively for glial fibrillary acidic protein. There were only a few acetylcholinesterase positive neurones in the mass. Most of the cells seemed to be primitive neuroectodermal cells with small axonal processes.

Under certain circumstances fetal neuronal tissue may continue to proliferate in a primitive form when transplanted into an adult host. Until the processes determining the relation between cell proliferation and differentiation are better understood it may not be possible to ensure that transplanted cells can be constrained appropriately. These cases involved cholinergic cells, but the same hazard may attend dopaminergic cell trans- plants. In evaluating fetal neuronal transplantation as a treatment for neurodegenerative diseases the possibility of serious deleterious effects on the hos should be considered.

R M RIDLEY H F BAKER

Division of Psychiatry,

Clinical Research Centre,

Harrow,

Middlesex HA1 3UJ

A Fine

Department of Physiology and Biophysics,

Dalhousie University,

Halifax,

Nova Scotia,

Canada

1 Ridley RM, Samson NA, Baker HF, et al. Visuospatial learnin mpairment following lesion of the cholinergic projection to the hippocampus. Brain Res (in press)

SIR,-Dr J M S Pearce (30 April, p 1211) and Dr Raanan Gillon (30 April, p 1212) raise important issues which are timely and instructive. We feel, however, that it is equally important to emphasise the lack of understanding of the mechanisms underlying re-establishment of central nervous system function and, in particular, the possible role of neurotrophic agents in this process.

To consider the basic mechanism solely in terms of cell transplantation may be to overlook its fundamental principle. It is possible that the host response to chemicals released from grafted cells is of greater importance than the synthesis and release of pharmacologically active catecholamines. The neurotrophic effects of synthetic and naturally occurring neuropeptides have been reported. ${ }^{1-3}$

Our current studies of the effect of neuropeptide fragments in countering experimental parkinsonism in rats encourage us to believe that grafted cells (including peripheral nerve cells ${ }^{4}$ ) may be serving merely as a vehicle for delivery of trophic agents or factors promoting their release. This concept has been proposed independently elsewhere ${ }^{5}$ and is substantiated by indirect evidence from animal studies. ${ }^{367}$ Investigation of the use of growth factors, even in the absence of grafted cells, may ultimately yield greater benefit than dopaminergic grafting.

ROBERT M REDFERN JOHN B MILES

Department of Neurosciences,

Walton Hospital,

Liverpool L9 IAE

Morley JS, Ensor DM. Neurotrophic effects of $\beta$-endorphi C-terminal tetrapeptide (MPF). Neuropeptides 1986;8:45-9.

2 Strömberg I, Herrera-Marschitz M, Ungerstedt U, Ebendal T,

Olson L. Chronic implants of chromaffin tissue into the dopamine-denervated striatum. Effects of NGF on graft survival, fiber growth and rotational behaviour. Exp Brain Res 1985;60:335-49.

3 Verhaagen J, Edwards PM, Jennekens FGI, Gispen WH. Pharmacological aspects of the influence of melanocortins on the formation of regenerative peripheral nerve sprouts. Peptides $1987 ; 8: 581-4$.

4 Freed WJ, Cannon-Spoor HE, Krauthamer E. Intrastriatal adrenal medulla grafts in rats: long-term survival and behavioural effects. 7 Neurosurg 1986;65:664-70.

Kish SJ, Shannak K, Hornykiewicz O. Uneven pattern of dopamine loss in the striatum of patients with idiopathic Parkinson's Disease. N Engl F Med 1988;318:876-80.

6 Kesslak JP, Nieto-Sampedro M, Globus J, Cotman CW. Transplants of purified astrocytes promote behavioural recovery after frontal cortex ablation. Exp Neurol 1986;92:377-90.

7 Freed WJ, Cannon-Spoor HE. Cortical lesions increase re innervation of the dorsal striatum by substantia nigra grafts. Brain Res 1988;446:133-43.

\section{Risk factors for ischaemic brain infarction}

SIR,-Dr Jaana Syrjänen and colleagues (23 April, p 1156) have shown that there is a strong association between recent infections and subsequent ischaemic brain infarctions. They offer some speculations about the mechanism, but this is still uncertain.

Blood fluidity is altered after bacterial infections. ${ }^{1}$ Our own unpublished data show that respiratory infections in particular induce a rise in plasma and blood viscosity. This is probably predominantly due to a rise in the concentrations of acute phase proteins. ${ }^{1}$ Such a haemorheological consequence of infection might influence brain perfusion, and various experiments show that the flow properties of blood are among the determinants of brain perfusion. ${ }^{2}$

One possible mechanism by which infections lead to brain infarctions is the limitation of blood fluidity. This could predispose to strokes, and virtually all known risk factors for stroke (smoking, hypertension, hyperlipoproteinaemia, high fibrinogen levels, and diabetes) are also associated with abnormalities in the flow properties of blood. ${ }^{4}$

Haemorheology Research Laboratory,

E ERNST

Department of Physical Medicine,

University of Munich

8000 Munich 2

Harkness J. The viscosity of human blood plasma: its measure ment in health and disease. Biorheology 1971;8:171-93.

2 Thomas DJ. Blood viscosity and cerebral blood flow. In Hartmann A, Kuschinsky W, eds. Cerebral ischemia and hemorheology. Heidelberg: Springer, 1987.

Ernst E, Matrai A, Marshall M. Blood rheology in patients with transient ischemic attacks. Stroke (in press).

Chien S, Dormandy J, Ernst E, Matrai A, eds. Clinical hemorheology. Dordrecht: M Nijhoff, 1987.

\section{Insulin for the non-insulin dependent?}

SIR,-Dr Roy Taylor (9 April, p 1015) assumes that improved blood glucose control is advantageous, although the most appropriate treatment for patients with non-insulin dependent diabetes will remain uncertain until the results of the United Kingdom prospective diabetes study are available. In younger patients with a long life expectancy blood glucose concentrations near to normal should be aimed for, whereas in older patients less tight control aiming merely to abolish symptoms may be more appropriate.

If an acceptable fasting blood glucose concentration cannot be achieved with diet and oral agents then a basal insulin supplement-for example, with once daily ultralente insulin-can be successful ${ }^{12}$ and does not carry the substantial risk of hypoglycaemia suggested by Dr Taylor. As this regimen aims primarily to reduce the fasting blood glucose concentration to normal there is no need to match individual meals to short acting insulin doses, and consequently there is less risk of hypoglycaemia should a meal be delayed or missed. Ultralente insulin is thus particularly useful in elderly patients living alone provided the dose is adjusted according to the fasting blood glucose concentration. Short and medium acting insulins, such as isophane and lente insulin, carry an increased risk of daytime hypoglycaemia in patients who still have a reasonable insulin secretory response to meals and are more useful in patients with a severely diminished secretory capacity who require additional insulin to cover meals. ${ }^{2}$

With failure of treatment with sulphonylureas it is a moot point whether they should be continued when insulin is started. Stimulation of endogenous insulin release by sulphonylurea allows a lower dose of insulin than would otherwise be needed. The gradual introduction of a long acting insulin to a patient who remains on maximum sulphonylurea treatment allows an easy transition even if one wishes eventually to withdraw the sulphonylurea. When a patient needs additional short acting 